\title{
Lymphatic malformation in the scrotum
}

\author{
Ajaykumar C. Morani • Nisha S. Ramani
}

Received: 21 February 2010 /Accepted: 30 March 2010/Published online: 7 May 2010

(C) Springer-Verlag 2010

A 6-month-old boy presented with right scrotal swelling since birth. It was soft and fluctuant with a positive transillumination test. Gray-scale US showed a multicystic extratesticular, extraepididymal mass in the right hemiscrotum (arrow), with moving internal echoes (Fig. 1). The septae showed flow on color Doppler (Fig. 2). Findings were suspicious for scrotal lymphatic malformation, confirmed on surgery. Lymphatic malformations are congenital lymphatic hamartomas. Ninety percent occur before 2 years of age and $95 \%$ occur in the neck or axilla. The scrotum is an uncommon site, and it may
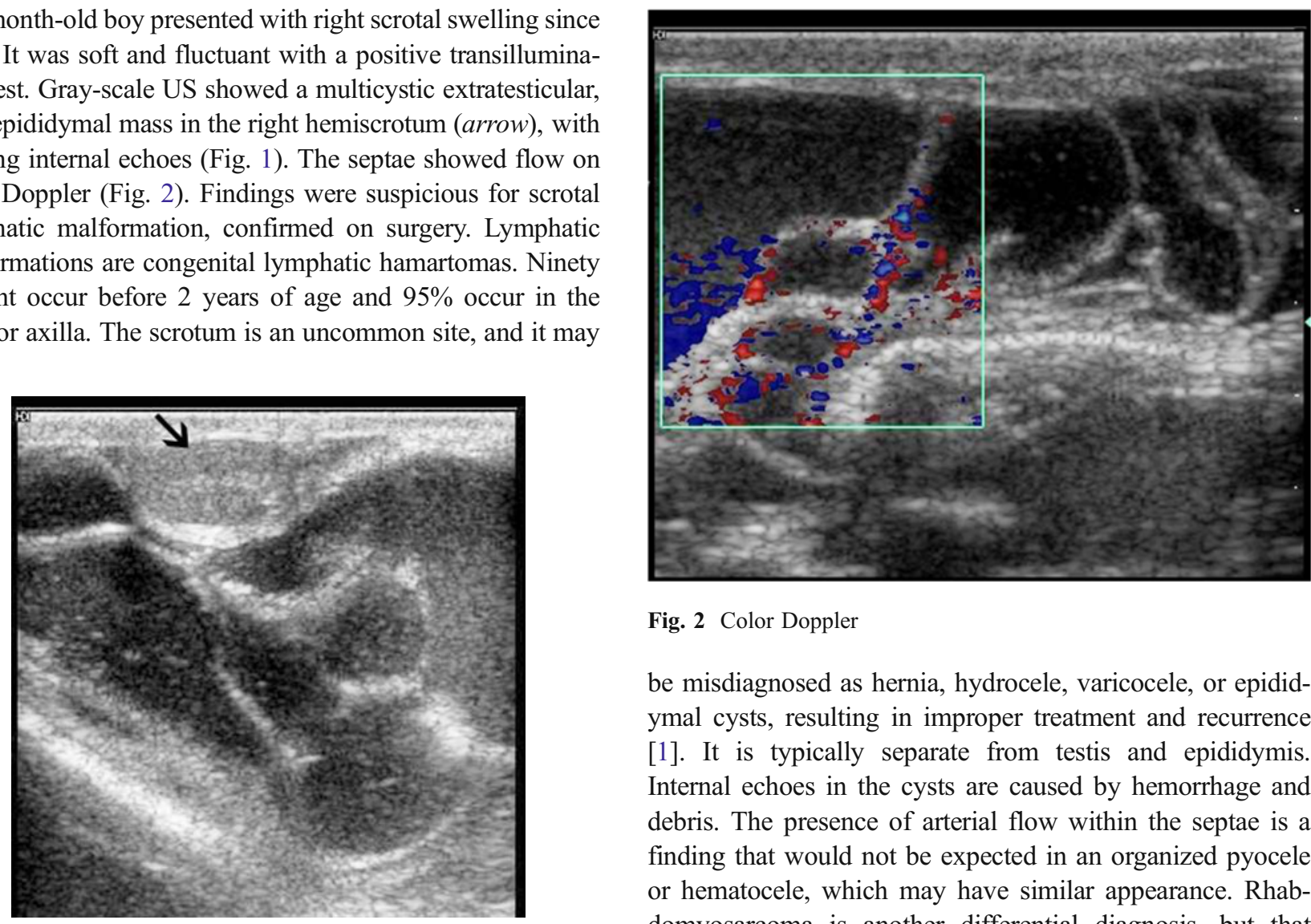

Fig. 2 Color Doppler

be misdiagnosed as hernia, hydrocele, varicocele, or epididymal cysts, resulting in improper treatment and recurrence [1]. It is typically separate from testis and epididymis. Internal echoes in the cysts are caused by hemorrhage and debris. The presence of arterial flow within the septae is a finding that would not be expected in an organized pyocele or hematocele, which may have similar appearance. Rhabdomyosarcoma is another differential diagnosis, but that appears as a complex solid-cystic mass [2].

\section{References}

A. C. Morani $(\bowtie)$

Department of Radiology, University of Michigan Health System, Ann Arbor, MI 48109-0030, USA

e-mail: amorani@med.umich.edu

\section{N. S. Ramani}

Department of Biochemistry, Sri Devraj URS Medical College,

Kolar, India

1. Singh S, Baboo ML, Pathak IC (1971) Cystic lymphangioma in children: report of 32 cases including lesions at rare sites. Surgery 69:947-951

2. Loberant N, Chernihovski A, Goldfeld M et al (2002) Role of Doppler sonography in the diagnosis of cystic lymphangioma of the scrotum. J Clin Ultrasound 30:384-387 